\title{
Review of Methods Used for Diagnosing Tuberculosis in Captive and Free-Ranging Non-Bovid Species (2012-2020)
}

\author{
Rebecca Thomas ${ }^{1}$ (D) and Mark Chambers ${ }^{1,2, *(D)}$ \\ 1 School of Veterinary Medicine, University of Surrey, VSM Building, Daphne Jackson Road, \\ Guildford, Surrey GU2 7AL, UK; rebecca.thomas22@virginmedia.com \\ 2 School of Biosciences and Medicine, University of Surrey, Edward Jenner Building, \\ Guildford, Surrey GU2 7XH, UK \\ * Correspondence: m.chambers@surrey.ac.uk; Tel.: +44-(0)-1483-684984
}

Citation: Thomas, R.; Chambers, M. Review of Methods Used for Diagnosing Tuberculosis in Captive and Free-Ranging Non-Bovid Species (2012-2020). Pathogens 2021, 10, 584 https://doi.org/10.3390/ pathogens 10050584

Academic Editors: Mitchell V. Palmer, Paola M. Boggiatto and Carly Kanipe

Received: 1 April 2021

Accepted: 7 May 2021

Published: 11 May 2021

Publisher's Note: MDPI stays neutral with regard to jurisdictional claims in published maps and institutional affiliations.

Copyright: (c) 2021 by the authors. Licensee MDPI, Basel, Switzerland. This article is an open access article distributed under the terms and conditions of the Creative Commons Attribution (CC BY) license (https:// creativecommons.org/licenses/by/ $4.0 /)$.

\begin{abstract}
The Mycobacterium tuberculosis complex (MTBC) is a group of bacteria that cause tuberculosis (TB) in diverse hosts, including captive and free-ranging wildlife species. There is significant research interest in developing immunodiagnostic tests for TB that are both rapid and reliable, to underpin disease surveillance and control. The aim of this study was to carry out an updated review of diagnostics for TB in non-bovid species with a focus predominantly on those based on measurement of immunity. A search was carried out to identify relevant papers meeting a pre-defined set of inclusion criteria. Forty-one papers were identified from this search, from which only twenty papers contained data to measure and compare diagnostic performance using diagnostic odds ratio. The diagnostic tests from each study were ranked based on sensitivity, specificity, and diagnostic odds ratio to define high performing tests. High sensitivity and specificity values across a range of species were reported for a new antigenic target, P22 complex, demonstrating it to be a reliable and accurate antigenic target. Since the last review of this kind was undertaken, the immunodiagnosis of TB in meerkats and African wild dogs was reported for the first time. Suid species showed the most consistent immunological responses and highlight a potential dichotomy between humoral and cellular immune responses.
\end{abstract}

Keywords: MTBC; Mycobacterium bovis; immunological; diagnostic; tuberculosis

\section{Introduction}

The Mycobacterium tuberculosis complex (MTBC) is a group of genetically similar bacteria that cause the disease tuberculosis (TB) in a range of hosts [1]. The MTBC comprises the major pathogenic mycobacteria species $M$. tuberculosis, M. bovis, M. africanum, M. canettii, M. microti, M. caprae, M. pinnipedii, M. mungi, M. suricattae, and M. orygis [2]. Cattle are considered the primary host of $M$. bovis; however, infection is not limited to livestock but also affects humans and many other free-ranging and captive wildlife species [3]. Notably, the European badger (Meles meles) in the United Kingdom, Brushtail possum (Trichosurus vulpecula) in New Zealand, and White-tailed deer (Odocoileus virginianus) in the United States are all species implicated in transmission of $M$. bovis to livestock [3]. As reviewed by Miller and Olea-Popelka, different control strategies for TB are implemented in different countries based on the level of disease transmission and prevalence within that country, and considering which species are infected or at risk of infection [4]. Common control strategies include surveillance, culling of reservoirs and infected animals, increased biosecurity and vaccination underpinned by diagnostic testing [5].

Zoonotic transmission of TB may be more likely in zoos due to the close contact of staff with animals, as well as the potential for transmission of infection from human to animal, although this is very rare [6]. In addition, zoos may find it problematic to maintain biodiversity and conserve valuable or endangered species and to exchange genetic resources and animals with one another where TB outbreaks occur, as reviewed by 
Lécu and Ball [7]. Accurate diagnosis of TB in captive wildlife is therefore important but challenging, given the diversity of species susceptible to the MTBC.

Conventional diagnostic tests for TB are considered the gold-standard and comprise of bacterial culture, histopathology, and post-mortem examination [8]. Often, these conventional tests are used in combination with one another or are used as a confirmatory test for newer immunological diagnostics, as discussed by Salfinger and Pfyffer [9]. Culture and post-mortem examinations are relatively expensive tests that require laboratory facilities for isolation and identification of mycobacteria. Culture is the primary gold-standard test for TB. However, as mycobacteria are slow growing, culture can be protracted as well as being liable to cross-contamination with other environmental bacteria [10]. Culture also varies in sensitivity depending upon the type of sample used [11].

Immunological diagnostics based on the humoral immune response rely on the detection of antibodies specific to MTBC antigens. Whilst easy to perform, they may be a poor indicator of TB infection because antibody titers tend to increase as disease progresses [12]. Hence, the humoral response is less reliable for the detection of asymptomatic cases or cases early on in infection but can be used to monitor the progress of infection, as reviewed in Pollock et al., 2001 [13]. Efforts to increase the sensitivity of antibody-based tests have included the use of multiple antigens, most recently, the P22 complex, made up of 118 different antigenic targets, including MPB83, MPB70 and ESAT-6 [14].

In contrast, the cell-mediated immune (CMI) response is characterized by the production of cytokines, such as IFN- $\gamma$ released by stimulated lymphocytes. As discussed in the Pollock et al. review, relative to antibody production, the CMI response generally occurs earlier after infection and is considered to play a major role in controlling TB [13]. The intradermal delayed-type hypersensitivity tuberculin skin test (TST) involves intradermal injection of tuberculin, a complex mix of antigens derived from M. bovis-purified protein derivative (PPD) and measurement of swelling at the injection site usually $72 \mathrm{hrs}$ later [15]. The TST is generally unreliable in most non-bovine species, such as European badgers, producing a weak response, which can be altered by the stress of capture [15,16]. In addition, the TST is often considered impractical for free-ranging wildlife because of the need to capture and retain the animal to read the test, as discussed and reviewed by De Lisle et al. [15].

Indicators often used to measure diagnostic test performance include, but are not limited to, sensitivity and specificity, predictive values, likelihood ratios, and receiver operating characteristic curve (ROC curve) analysis. Another, but less used, method is the diagnostic odds ratio (DOR). The DOR is a single indicator of test performance, being a ratio of the odds of a positive result in a diseased individual relative to the odds of a positive result in a non-diseased individual [17]. DOR can range from 0 to infinity, but a value of 1 demonstrates that the test has no discrimination between an individual with and without disease. The higher the DOR value, the better able a test is in discriminating infected from non-infected individuals [17].

The aim of the current project was to perform a review of diagnostics used for the detection of TB in free-ranging and captive wildlife species with a focus predominantly on those based on measurement of immunity, updating on previous reviews published in 2009 and 2013 [18,19]. Different studies identifying new or modified immunological targets and techniques in either known or novel wildlife reservoirs were identified and explored to evaluate the performance of the diagnostic technique and approaches used. The DOR was used to determine the performance of diagnostic tests for TB, not having previously been used for this purpose in animal studies.

\section{Results}

\subsection{Summary of Reported Techniques and Species since 2012}

A total of 41 papers were identified and considered as relevant. Table 1 shows the test employed, test target, MTBC species, the nature of infection (natural or experimental), and the species of animal being observed for these 41 papers. 
Table 1. Summary of forty-one relevant results from a PubMed search identifying papers from 2012 to present, looking at diagnostic tests for TB in free-ranging and captive non-bovid wildlife.

\begin{tabular}{|c|c|c|c|c|c|}
\hline $\begin{array}{l}\text { Mycobacterium } \\
\text { Species }\end{array}$ & $\begin{array}{l}\text { Natural (N) or } \\
\text { Experimental (E) } \\
\text { Infection }^{1}\end{array}$ & Species & $\begin{array}{l}\text { Technique } \\
\text { Employed }\end{array}$ & Target & Reference \\
\hline $\begin{array}{c}\text { M. tuberculosis and } \\
\text { M. bovis }\end{array}$ & N (333) & $\begin{array}{l}\text { Deer (Cervus unicolor } \\
\text { swinhoei and } \\
\text { C. nippon taiouanus) }\end{array}$ & $\begin{array}{l}\text { Culture, mnPCR, SITT, } \\
\text { Acid fast stain }\end{array}$ & NA & [20] \\
\hline M. bovis & $N(483)+E(31)$ & $\begin{array}{c}\text { White-Tailed Deer } \\
\text { (Odocoileus } \\
\text { virginianus) }\end{array}$ & DPP VetTB Assay & MPB83, CFP10, ESAT-6 & [21] \\
\hline M. bovis & $\mathrm{N}(75)$ & $\begin{array}{l}\text { White Rhinoceros } \\
\text { (Ceratotherium simum) }\end{array}$ & IGRA & bPPD, aPPD & [22] \\
\hline МТВC & N (2080) & $\begin{array}{l}\text { Wild boar } \\
\text { (Sus scrofa) }\end{array}$ & bPPD ELISA & NA & [23] \\
\hline M. bovis & $\mathrm{N}(5)+\mathrm{E}(15)$ & $\begin{array}{l}\text { Red Deer } \\
\text { (Cervus elaphus) }\end{array}$ & EVELISA & NA & [24] \\
\hline M. bovis & $N(7)+E(9)$ & $\begin{array}{l}\text { White-Tailed Deer } \\
\text { (Odocoileus } \\
\text { virginianus) }\end{array}$ & EVELISA & MPB83 & [25] \\
\hline M. bovis & $N(126)$ & Wild Boar (Sus scrofa) & $\begin{array}{l}\text { DPP VetTB, ELISA IgG, } \\
\text { ELISA DR, ELISA IgM, } \\
\text { Culture }\end{array}$ & $\begin{array}{l}\text { MPB70, MPB83, CFP10, } \\
\text { ESAT-6, bPPD, IgG, IgM }\end{array}$ & [26] \\
\hline M. bovis & $\mathrm{N}(\mathrm{ND})$ & $\begin{array}{l}\text { European Badger } \\
\text { (Meles meles) }\end{array}$ & $\begin{array}{l}\text { STAT-PAK, IGRA, } \\
\text { qPCR, Culture }\end{array}$ & $\begin{array}{c}\text { MPB83, ESAT-6, CFP10, } \\
\text { bPPD, aPPD }\end{array}$ & [27] \\
\hline M. tuberculosis & $\mathrm{N}(1)$ & $\begin{array}{l}\text { Black Rhinoceros } \\
\text { (Diceros bicornis) }\end{array}$ & $\begin{array}{c}\text { STAT-PAK, DPP VetTB, } \\
\text { MAPIA }\end{array}$ & MPB83, ESAT-6, CFP10 & [28] \\
\hline M. bovis & $\mathrm{N}(751)$ & $\begin{array}{l}\text { European Badger } \\
\text { (Meles meles) }\end{array}$ & $\begin{array}{c}\text { IGRA, STAT-PAK } \\
\text { Assays }\end{array}$ & $\begin{array}{l}\text { bPPD, aPPD, MPB83, } \\
\text { ESAT-6, CFP10, MPB70 }\end{array}$ & [29] \\
\hline M. tuberculosis & $\mathrm{N}(5)$ & $\begin{array}{l}\text { Asian elephant } \\
\text { (Elephas maximus) }\end{array}$ & $\begin{array}{l}\text { DPP VetTB Assay, } \\
\text { STAT-PAK }\end{array}$ & MPB83, ESAT-6, CFP10 & [30] \\
\hline M. suricattae & N (111) & $\begin{array}{l}\text { Meerkat } \\
\text { (Suricata suricatta) } \\
\text { Warthog }\end{array}$ & Cytokine Release Assay & PC-HP peptide pool & [31] \\
\hline M. bovis & $\mathrm{N}(3)$ & $\begin{array}{c}\text { (Phacochoerus } \\
\text { africanus) }\end{array}$ & DPP VetTB Assay & MPB83, CFP10, ESAT-6 & [32] \\
\hline M. bovis & N (35) & $\begin{array}{l}\text { Warthog } \\
\text { (Phacochoerus } \\
\text { africanus) }\end{array}$ & $\begin{array}{c}\text { Indirect PPD ELISA, TB } \\
\text { ELISA-VK, DPP VetTB } \\
\text { Assay }\end{array}$ & $\begin{array}{l}\text { bPPD, MPB83, ESAT-6, } \\
\text { CFP10 }\end{array}$ & [33] \\
\hline M. tuberculosis & $\mathrm{N}(\mathrm{ND})$ & $\begin{array}{l}\text { Asian Elephant } \\
\text { (Loxodonta africana) }\end{array}$ & $\begin{array}{c}\text { STAT-PAK, DPP VetTB } \\
\text { Assay }\end{array}$ & MPB83, ESAT-6, CFP10 & [34] \\
\hline M. bovis & $\mathrm{N}(474)$ & $\begin{array}{l}\text { Red Deer } \\
\text { (Cervus elaphus) }\end{array}$ & $\begin{array}{c}\text { STAT-PAK, DPP VetTB, } \\
\text { MAPIA }\end{array}$ & $\begin{array}{c}\text { MPB83, ESAT-6, CFP10, } \\
\text { bPPD, MPB70 }\end{array}$ & [35] \\
\hline M. bovis & N (550) & $\begin{array}{l}\text { European Badger } \\
\text { (Meles meles) }\end{array}$ & $\begin{array}{l}\text { IGRA, STAT-PAK, } \\
\text { Culture }\end{array}$ & $\begin{array}{c}\text { bPPD, aPPD, MPB83, } \\
\text { ESAT-6, CFP10 }\end{array}$ & [36] \\
\hline МТВС & $\mathrm{N}(217)$ & $\begin{array}{c}\text { Domestic Pig }^{2} \\
\text { (Sus scrofa domesticus) }\end{array}$ & $\begin{array}{c}\text { bPPD ELISA, INgezim } \\
\text { TB Porcine, INgezim } \\
\text { TB-CROM }\end{array}$ & MPB70, MPB83, bPPD & [37] \\
\hline МТВC & N (173) & $\begin{array}{l}\text { European Badger } \\
\text { (Meles meles) }\end{array}$ & IgG ELISA & MPB83, Rv2873 & [38] \\
\hline M. bovis & N (14) & $\begin{array}{l}\text { African Lion } \\
\text { (Panthera leo) }\end{array}$ & qPCR & $\begin{array}{c}\text { MIG/CXCL9, ESAT-6, } \\
\text { CFP-10 }\end{array}$ & [39] \\
\hline M. bovis & E (3) & $\begin{array}{l}\text { White Rhinoceros } \\
\text { (Ceratotherium simum) }\end{array}$ & $\begin{array}{c}\text { PPD ELISA, TB } \\
\text { STAT-PAK, DPP VetTB } \\
\text { Assay }\end{array}$ & $\begin{array}{l}\text { bPPD, aPPD, MPB83, } \\
\text { ESAT-6, CFP10, MPB70 }\end{array}$ & [40] \\
\hline МТВC & N (35) & $\begin{array}{l}\text { African elephant } \\
\text { (Loxodonta africana) }\end{array}$ & $\begin{array}{c}\text { Elephant TB STAT-PAK, } \\
\text { DPP VetTB Assay }\end{array}$ & MPB83, ESAT-6, CFP10 & [41] \\
\hline M. bovis & N (541) & $\begin{array}{l}\text { European Badger } \\
\text { (Meles meles) }\end{array}$ & $\begin{array}{l}\text { IMS LFA, qPCR, } \\
\text { Culture }\end{array}$ & M. bovis whole cells & [42] \\
\hline M. bovis & $\mathrm{N}(88)$ & $\begin{array}{l}\text { Warthog } \\
\text { (Phacochoerus } \\
\text { africanus) }\end{array}$ & Cytokine Release Assay & $\begin{array}{l}\text { ESAT-6, CFP-10, TB7.7 } \\
\text { peptides }\end{array}$ & [43] \\
\hline M. bovis & $\mathrm{N}(170)$ & $\begin{array}{l}\text { Warthog } \\
\text { (Phacochoerus } \\
\text { africanus) } \\
\text { Warthog }\end{array}$ & $\begin{array}{c}\text { Indirect PPD ELISA, TB } \\
\text { ELISA-VK }\end{array}$ & bPPD & [44] \\
\hline M. bovis & N (34) & $\begin{array}{c}\text { (Phacochoerus } \\
\text { africanus) }\end{array}$ & SITT, CITT & bPPD, aPPD & [45] \\
\hline M. bovis & N (678) & Wild Boar (Sus scrofa) & bPPD ELISA & bPPD & [46] \\
\hline M. bovis & $N(131)+E(2)$ & $\begin{array}{l}\text { White Rhinoceros } \\
\text { (Ceratotherium simum) }\end{array}$ & IGRA & ESAT-6, CFP10 & [47] \\
\hline M. bovis & $\mathrm{E}(\mathrm{ND})$ & $\begin{array}{l}\text { European Badger } \\
\text { (Meles meles) }\end{array}$ & MPB83-IgA ELISA & MPB83 specific-IgA & [48] \\
\hline M. bovis & $N(55)+E(51)$ & Wild Boar (Sus scrofa) & $\begin{array}{l}\text { INgezim TB CROM } \\
\text { (LFA), INgezim TB } \\
\text { Porcine and INgezim } \\
\text { Tuberculosis DR, } \\
\text { Indirect ELISA }\end{array}$ & $\begin{array}{l}\text { MPB83, MPB70, P22 } \\
\text { complex }\end{array}$ & [49] \\
\hline
\end{tabular}


Table 1. Cont.

\begin{tabular}{|c|c|c|c|c|c|}
\hline $\begin{array}{l}\text { Mycobacterium } \\
\text { Species }\end{array}$ & $\begin{array}{c}\text { Natural (N) or } \\
\text { Experimental (E) } \\
\text { Infection }^{1}\end{array}$ & Species & $\begin{array}{l}\text { Technique } \\
\text { Employed }\end{array}$ & Target & Reference \\
\hline M. bovis & N (40) & $\begin{array}{l}\text { African wild dog } \\
\text { (Lycaon pictus) }\end{array}$ & IGRA & ESAT-6, CFP10 & {$[50]$} \\
\hline МТВC & $N(85)+E(36)$ & $\begin{array}{l}\text { European Badger } \\
\text { (Meles meles) }\end{array}$ & P22 ELISA & P22 complex & {$[51]$} \\
\hline MTBC & N (222) & $\begin{array}{l}\text { African Elephant } \\
\text { (Loxodonta africana) }\end{array}$ & $\begin{array}{l}\text { STAT-PAK Assay, DPP } \\
\text { Vet TB Assay }\end{array}$ & MPB83, ESAT-6, CFP10 & {$[52]$} \\
\hline M. bovis & N (326) & Lion (Panthera leo) & $\begin{array}{l}\text { STAT-PAK, DPP Vet TB, } \\
\text { SITT }\end{array}$ & $\begin{array}{l}\text { MPB83, ESAT-6, CFP10, } \\
\text { bPPD }\end{array}$ & [53] \\
\hline M. bovis & N (79) & $\begin{array}{l}\text { Wild Boar (Sus scrofa), } \\
\text { Warthog } \\
\text { (Phacochoerus } \\
\text { africanus) }\end{array}$ & DPP VetTB Assay & $\begin{array}{c}\text { IgG, MPB83, CFP10, } \\
\text { ESAT-6 }\end{array}$ & [54] \\
\hline M. bovis & N (495) & Wild Boar (Sus scrofa) & $\begin{array}{l}\text { PCR, IDEXX Ab test, } \\
\text { INgezim TB porcine, } \\
\text { TB ELISA-VK }\end{array}$ & bPPD, MPB83, MPB70 & [55] \\
\hline M. bovis & N (15) & $\begin{array}{l}\text { Warthog } \\
\text { (Phacochoerus } \\
\text { africanus) }\end{array}$ & GEA & ESAT-6, CFP10 & [56] \\
\hline MTBC & N (277) & Wild Boar (Sus scrofa) & $\begin{array}{l}\text { P22 ELISA, bPPD } \\
\text { ELISA }\end{array}$ & P22 complex, bPPD & {$[57]$} \\
\hline MTBC & N (221) & $\begin{array}{l}\text { Red Deer } \\
\text { (Cervus elaphus) }\end{array}$ & $\begin{array}{l}\text { P22 ELISA, bPPD } \\
\text { ELISA }\end{array}$ & P22 complex, bPPD & [58] \\
\hline MTBC & N (88) & $\begin{array}{l}\text { Red Deer } \\
\text { (Cervus elaphus) }\end{array}$ & CITT, Serum Hp & Нр & [59] \\
\hline M. bovis & $N(62)$ & $\begin{array}{l}\text { African Lion } \\
\text { (Panthera leo) }\end{array}$ & CITT, GEA & bPPD, aPPD & [60] \\
\hline
\end{tabular}

${ }^{1}$ Number in parenthesis indicates samples size, ND indicates precise number could not be determined from the paper, e.g., specify trapping events rather than individuals. ${ }^{2}$ Domestic pigs were exceptionally included here as the study was carried out on domestic free-range Iberian pigs reared outdoors and sharing natural resources with other wild and domestic animals, including cattle and wildlife. mn, Multiplex nested; q, real-time; PCR, Polymerase Chain Reaction; SITT, Single Intradermal Tuberculin Test; CITT, Comparative Intradermal Tuberculin Test; DPP, Dual Platform Pathway; PC-HP peptide pool, contains ESAT- 6 and CFP $\neg 10$ peptides and antigens derived from the gene Rv3615c and an additional three genes [61]; IGRA, Interferon-Gamma Release Assay; ELISA, Enzyme-linked Immunosorbent Assay; EVELISA, Ethanol Vortex ELISA; STAT-PAK (Chembio Diagnostic Systems, Inc.)/LFA, Lateral Flow Assay; MAPIA, Multi-antigen Print Immunoassay; (b)PPD, (Bovine) Purified Protein Derivative; IMS, Immunomagnetic Separation; GEA, Gene Expression Assay; Hp, Haptoglobin; NA = Not Applicable, was not indicated in the study.

Using the data from Table 1, the most frequently used diagnostic tests, target antigens, and studied species were identified. First, it was noted that the most common species studied were wild boar (Sus scrofa), deer, and badgers (Meles meles), with each species appearing in seven individual studies ( $16.7 \%$ each of the total), closely followed by warthogs (Phacochoerus africanus), which appeared in six studies (14.3\%) (Table 1). The animals of these species were a range of wild and captive animals, with the deer being a mix of red deer (Cervus elaphus) and white-tailed deer (Odocoileus virginianus). Species which appeared in fewer studies included elephants (Elephas maximus and Loxodonta africana), lions (Panthera leo) and rhinoceros (Ceratotherium simum). Meerkats (Suricata suricatta) and African wild $\operatorname{dog}$ (Lycaon pictus) were reported for the first time in this context, each being the focus of one study (Table 1).

The most common techniques used within the 41 studies were ELISAs and Lateral Flow devices (LFD), consisting of INgezim TB-CROM (Eurofins Technologies Ingenasa, Madrid, Spain), STAT-PAK (Chembio Diagnostic Systems, Inc., Hauppauge, NY, USA), and Dual Path Platform (DPP) VetTB assay (Chembio Diagnostic Systems, Inc.). Other tests included tests of CMI, such as the Interferon-Gamma Release Assay (IGRA) and TST (both the Comparative Intradermal Tuberculin Test (CITT) and the Single Intradermal Tuberculin Test (SITT)) (Table 1). However, it was evident that serological tests were more frequently selected approaches than those based on CMI.

In parallel with the most common techniques used, the most recurrent antigenic targets were revealed. Most tests used the same or similar antigens, or a mixture of recombinant proteins (Table 1). For instance, bPPD, MPB70, MPB83, ESAT-6, and CFP10 were commonly used as either individual targets or mixed as a cocktail of either ESAT-6 and CFP10 or MPB70 and MPB83. The P22 complex protein [14] was used in a range of lateral flow assays or a 'P22 ELISA'. 


\subsection{Statistical Analysis}

From the 41 papers, 20 contained data with which to carry out statistical analysis, calculating, if not stated, sensitivity, specificity, negative and positive predictive values (NPV, PPV), DOR, and where suitable the corresponding 95\% confidence intervals (95\% CI). The false negative and false positive (FN, FP), true negative and true positive (TN, TP) rates were calculated and used in a statistical test to create another set of data (Table 2) that could be used to compare diagnostic performance. The DOR was used as a measure of diagnostic performance, being the ratio of the odds of a positive result in a diseased individual relative to the odds of a positive result in a non-diseased individual [17]. The remaining 22 papers were evaluated, but no statistical analysis was conducted because the appropriate information was missing from the paper, such as true infection status.

Table 2. Summary of forty-one relevant results from a PubMed search identifying papers from 2012 to present, looking at diagnostic tests for TB in free-ranging and captive non-bovid wildlife.

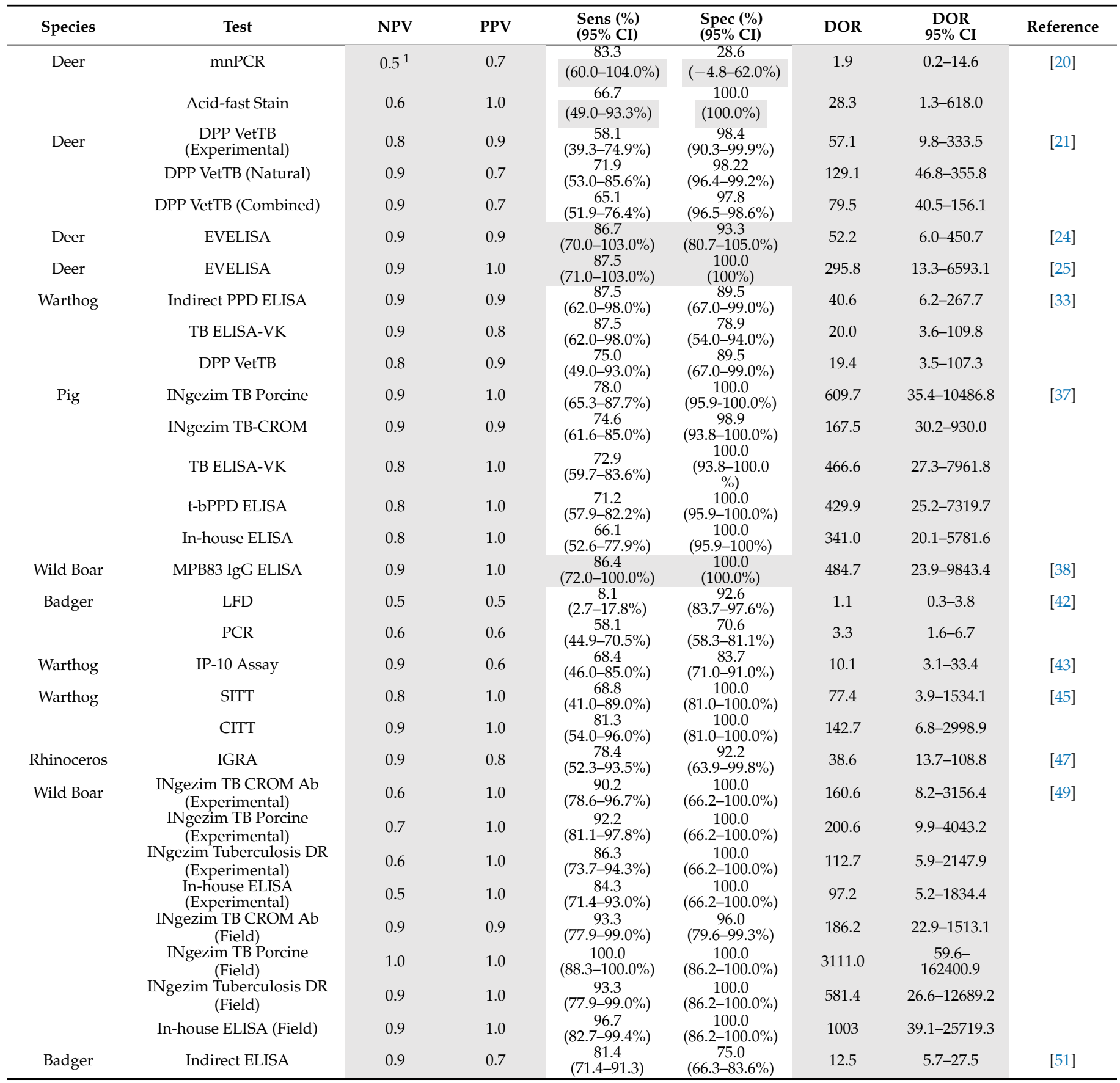


Table 2. Cont.

\begin{tabular}{|c|c|c|c|c|c|c|c|c|}
\hline Species & Test & NPV & PPV & $\begin{array}{l}\text { Sens (\%) } \\
(95 \% \text { CI) }\end{array}$ & $\begin{array}{l}\text { Spec (\%) } \\
(95 \% \text { CI) }\end{array}$ & DOR & $\begin{array}{c}\text { DOR } \\
\mathbf{9 5 \%} \text { CI }\end{array}$ & Reference \\
\hline \multirow{3}{*}{ Lion } & Competitive ELISA & 0.9 & 0.8 & $\begin{array}{c}78.0 \\
(67.0-88.0 \%)\end{array}$ & $\begin{array}{c}89.6 \\
(83.0-95.6 \%)\end{array}$ & 28.4 & $11.7-68.5$ & \multirow{3}{*}{ [53] } \\
\hline & STAT-PAK & 0.8 & 1.0 & $\begin{array}{c}62.5 \\
(35.0-85.0 \%)\end{array}$ & $\begin{array}{c}100.0 \\
(78.0-100.0 \%)\end{array}$ & 69.5 & $3.6-1353.5$ & \\
\hline & SITT & 0.8 & 0.7 & $\begin{array}{c}72.7 \\
(39.0-94.0 \%)\end{array}$ & $\begin{array}{c}80.0 \\
(52.0-96.0 \%)\end{array}$ & 8.7 & $1.6-48.4$ & \\
\hline \multirow[t]{2}{*}{$\begin{array}{l}\text { Warthog, } \\
\text { Wild Boar }\end{array}$} & $\begin{array}{c}\text { DPP VetTB Assay (Wild } \\
\text { Boar) }\end{array}$ & 0.7 & 0.9 & $\begin{array}{c}80.4 \\
(68.0-88.0 \%)\end{array}$ & $\begin{array}{c}96.7 \\
(81.9-100.0 \%)\end{array}$ & 77.8 & $13.3-453.8$ & \multirow[t]{2}{*}{ [54] } \\
\hline & $\begin{array}{c}\text { DPP VetTB Assay } \\
\text { (Warthog) }\end{array}$ & 0.9 & 0.9 & $\begin{array}{c}82.6 \\
(62.3-93.6 \%)\end{array}$ & $\begin{array}{c}91.4 \\
(76.9-97.8 \%)\end{array}$ & 40.2 & $8.9-181.3$ & \\
\hline \multirow[t]{5}{*}{ Wild Boar } & PCR & 0.9 & 0.3 & $\begin{array}{c}62.5 \\
(24.6-91.5 \%)\end{array}$ & $\begin{array}{c}97.1 \\
(94.8-98.5 \%)\end{array}$ & 50.2 & $11.6-216.9$ & \multirow[t]{2}{*}{ [55] } \\
\hline & TB ELISA-VK (0.2 Cut-off) & 1.0 & 0.1 & $\begin{array}{c}85.7 \\
(42.1-99.6 \%)\end{array}$ & $\begin{array}{c}87.5 \\
(83.7-90.6 \%)\end{array}$ & 30.0 & $4.9-181.5$ & \\
\hline & TB ELISA-VK (0.5 Cut-off) & 0.9 & 0.4 & $\begin{array}{c}85.7 \\
(42.1-99.6 \%)\end{array}$ & $\begin{array}{c}97.3 \\
(95.2-98.7 \%)\end{array}$ & 150.8 & $23.1-987.0$ & \multirow{8}{*}{ [56] } \\
\hline & IDEXX & 1.0 & 0.3 & $\begin{array}{c}75 \\
(34.9-96.8 \%)\end{array}$ & $\begin{array}{c}96.7 \\
(94.7-98.1 \%)\end{array}$ & 74.1 & $15.9-345.5$ & \\
\hline & INgezim TB Porcine & 0.9 & 0.3 & $\begin{array}{c}75 \\
(34.9-96.8 \%)\end{array}$ & $\begin{array}{c}96.9 \\
(94.9-98.3 \%)\end{array}$ & 79.1 & $16.9-370.4$ & \\
\hline \multirow[t]{5}{*}{ Warthog } & GEA (CXCL9) & 0.7 & 0.9 & $\begin{array}{c}60.0 \\
(32.0-84.0 \%)\end{array}$ & $\begin{array}{c}94.1 \\
(71.0-100.0 \%)\end{array}$ & 16.1 & $2.3-112.6$ & \\
\hline & GEA (CXCL10) & 0.9 & 0.9 & $\begin{array}{c}86.7 \\
(60.0-98.0 \%)\end{array}$ & $\begin{array}{c}94.1 \\
(71.0-100.0 \%)\end{array}$ & 59.4 & $6.9-509.1$ & \\
\hline & GEA (CXCL11) & 0.7 & 1.0 & $\begin{array}{c}53.3 \\
(27.0-79.0 \%)\end{array}$ & $\begin{array}{c}100.0 \\
(80.0-100.0 \%)\end{array}$ & 39.7 & $2.0-779.2$ & \\
\hline & GEA $($ TNF- $\alpha)$ & 0.8 & 0.8 & $\begin{array}{c}73.3 \\
(45.0-92.0 \%)\end{array}$ & $\begin{array}{c}88.2 \\
(64.0-99.0 \%)\end{array}$ & 15.8 & $2.8-88.8$ & \\
\hline & GEA $($ IFN- $\gamma)$ & 0.8 & 0.8 & $\begin{array}{c}80.0 \\
(52.0-96.0 \%)\end{array}$ & $\begin{array}{c}82.4 \\
(57.0-96.0 \%)\end{array}$ & 14.8 & $2.8-78.1$ & \\
\hline \multirow[t]{2}{*}{$\begin{array}{l}\text { Wild Boar, } \\
\text { Pig }\end{array}$} & P22 ELISA & 0.9 & 0.9 & $\begin{array}{c}84.1 \\
(79.3-98.4 \%)\end{array}$ & $\begin{array}{c}98.4 \\
(96.5-99.4 \%)\end{array}$ & 291.0 & $125.7-673.6$ & \multirow[t]{2}{*}{ [57] } \\
\hline & bPPD ELISA & 0.8 & 0.9 & $\begin{array}{c}77.3 \\
(71.9-82.1 \%)\end{array}$ & $\begin{array}{c}97.3 \\
(95.0-98.3 \%)\end{array}$ & 114.7 & $58.4-225.2$ & \\
\hline Deer & P22 ELISA & 0.8 & 1.0 & $\begin{array}{c}70.1 \\
(63.6-76.0 \%)\end{array}$ & $\begin{array}{c}99.0 \\
(96.5-99.8 \%)\end{array}$ & 189.4 & $52.7-681.1$ & [58] \\
\hline \multirow{3}{*}{ Deer } & bPPD ELISA & 0.7 & 0.9 & $\begin{array}{c}70.1 \\
(63.6-76.0 \%)\end{array}$ & $\begin{array}{c}91.6 \\
(86.9-95.0 \%)\end{array}$ & 25.1 & $14.2-44.2$ & \multirow{3}{*}{ [59] } \\
\hline & CITT & 0.8 & 0.5 & $\begin{array}{r}25.0 \\
(-5.0-55.0 \%)\end{array}$ & $\begin{array}{c}92.0 \\
(81.3-102.6 \%)\end{array}$ & 3.6 & $0.5-25.6$ & \\
\hline & $\mathrm{Hp}$ & 0.9 & 0.7 & $\begin{array}{c}62.5 \\
(28.9-96.0 \%)\end{array}$ & $\begin{array}{c}92.0 \\
(81.0-102.0 \%)\end{array}$ & 14.8 & $2.3-95.8$ & \\
\hline
\end{tabular}

${ }^{1}$ Shaded cells indicate values that were calculated by us and not provided in the original study.

\subsection{Analyzing Diagnostic Performance}

Diagnostic performance was compared across all tests from the twenty studies in Table 2. Data were ordered to find the top ten best performing and lowest ten performing tests based on sensitivity, specificity, and DOR, individually (Tables 3 and 4). The 95\% CI overlapped for nearly all diagnostic tests as many DOR calculations had a large $95 \%$ CI; therefore, the tests were simply ranked based on the calculated DOR. Fifty-three\% of top-ranking tests were carried out in wild boar, with $8 / 10$ (80\%) of the DOR top ranking tests used in suid species. The INgezim TB Porcine test used for wild boar had the highest sensitivity $(100 \%)$, specificity $(100 \%)$, and DOR (3111) of any test (Table 3$)$. This was followed by the DPP VetTB assay and an in-house ELISA [49] based on antibody recognition of the P22 protein complex, also tested in suid species. The most frequently used antigenic targets in the top-ranking tests were MPB83, MPB70, P22 complex, ESAT-6, and CFP10. In contrast, the lower ranking tests consisted of more CMI diagnostics, such as the TST. Based on the DOR, the worst performing test were an LFD using an IgG cocktail of commercial anti-mouse IgG and anti-rabbit IgG [42] (DOR, 1.1) and both CITT and SITT. Antigenic targets among the more poorly performing tests included bPPD and MPB83, although MPB83 featured infrequently in comparison to bPPD. Additionally, the lowest ranking tests were carried out on deer, badgers, and lions, with a few studies on warthogs and wild boar. Notably, the TB ELISA-VK using bPPD as a target [33] was ranked within the top 10 for sensitivity but within the lowest 10 for specificity and did not appear among either of the rankings according to DOR. 
Table 3. The ten best performing tests in non-bovid wildlife ranked based on highest values for sensitivity, specificity, and diagnostic odds ratio (DOR).

\begin{tabular}{|c|c|c|c|c|c|c|c|c|c|}
\hline \multirow{2}{*}{$\begin{array}{l}\text { Ranking } \\
\text { Position }\end{array}$} & \multicolumn{3}{|c|}{ Top 10 Tests-Sensitivity } & \multicolumn{3}{|c|}{ Top 10 Tests-Specificity } & \multicolumn{3}{|c|}{ Top 10 Tests-DOR } \\
\hline & Test & Species & Ag & Test & Species & Ag & Test & Species & Ag \\
\hline 1 & $\begin{array}{c}\text { INgezim TB } \\
\text { Porcine }\left(\mathrm{F}^{1}\right) \\
{[49]}\end{array}$ & Wild Boar & MPB83/ 70 & $\begin{array}{c}\text { INgezim TB } \\
\text { Porcine (F) } \\
{[49]}\end{array}$ & Wild Boar & MPB83/ 70 & $\begin{array}{c}\text { INgezim TB } \\
\text { Porcine (F) } \\
\text { [49] }\end{array}$ & Wild Boar & MPB83/70 \\
\hline 2 & $\begin{array}{l}\text { In-house } \\
\text { ELISA (F) } \\
\text { [49] }\end{array}$ & Wild Boar & $\begin{array}{c}\text { P22 } \\
\text { complex }\end{array}$ & $\begin{array}{l}\text { In-house } \\
\text { ELISA (F) } \\
\text { [49] }\end{array}$ & Wild Boar & $\begin{array}{c}\text { P22 } \\
\text { complex }\end{array}$ & $\begin{array}{l}\text { DPP VetTB } \\
\text { Assay [54] }\end{array}$ & Pig & $\begin{array}{l}\text { MPB83/ESAT- } \\
\text { 6/CFP10 }\end{array}$ \\
\hline 3 & $\begin{array}{l}\text { DPP VetTB } \\
\text { Assay [54] }\end{array}$ & Pig & $\begin{array}{l}\text { MPB83/ESAT- } \\
\text { 6/CFP10 }\end{array}$ & $\begin{array}{l}\text { DPP VetTB } \\
\text { Assay [54] }\end{array}$ & Pig & $\begin{array}{l}\text { MPB83/ } \\
\text { ESAT-6/ } \\
\text { CFP10 }\end{array}$ & $\begin{array}{c}\text { In-house } \\
\text { ELISA (F) } \\
\text { [49] }\end{array}$ & Wild Boar & $\begin{array}{c}\text { P22 } \\
\text { complex }\end{array}$ \\
\hline 4 & $\begin{array}{l}\text { INgezim } \\
\text { TB-CROM } \\
\text { (F) [49] }\end{array}$ & Wild Boar & MPB83 & $\begin{array}{l}\text { INgezim Tu- } \\
\text { berculosis } \\
\text { DR (F) [49] }\end{array}$ & Wild Boar & MPB83 & $\begin{array}{l}\text { INgezim TB } \\
\text { Porcine [37] }\end{array}$ & Pig & MPB83/70 \\
\hline 5 & $\begin{array}{l}\text { INgezim Tu- } \\
\text { berculosis } \\
\text { DR (F) [49] }\end{array}$ & Wild Boar & MPB83 & $\begin{array}{l}\text { INgezim TB } \\
\text { Porcine (E) } \\
\text { [49] }\end{array}$ & Wild Boar & MPB83/ 70 & $\begin{array}{l}\text { INgezim Tu- } \\
\text { berculosis } \\
\text { DR (F) [49] }\end{array}$ & Wild Boar & MP83 \\
\hline 6 & $\begin{array}{l}\text { INgezim TB } \\
\text { Porcine (E } \\
\text { 2) [49] }\end{array}$ & Wild Boar & MPB83/ 70 & $\begin{array}{l}\text { INgezim } \\
\text { TB-CROM } \\
\text { (E) [49] }\end{array}$ & Wild Boar & MPB83 & $\begin{array}{l}\text { MPB83 IgG } \\
\text { ELISA [38] }\end{array}$ & Badger & MPB83 \\
\hline 7 & $\begin{array}{l}\text { INgezim } \\
\text { TB-CROM } \\
\text { (E) [49] }\end{array}$ & Wild Boar & MPB83 & $\begin{array}{c}\text { EVELISA } \\
{[25]}\end{array}$ & Deer & MPB83 & $\begin{array}{c}\text { TB } \\
\text { ELISA-VK } \\
{[37]}\end{array}$ & Pig & bPPD \\
\hline 8 & $\begin{array}{l}\text { EVELISA } \\
\text { [25] }\end{array}$ & Deer & MPB83 & $\begin{array}{c}\text { MPB83 IgG } \\
\text { ELISA [38] }\end{array}$ & Badger & MPB83 & $\begin{array}{c}\text { t-bPPD } \\
\text { In-house } \\
\text { ELISA [37] }\end{array}$ & Pig & $\begin{array}{l}\text { Treated } \\
\text { bPPD }\end{array}$ \\
\hline 9 & $\begin{array}{c}\text { Indirect } \\
\text { PPD ELISA } \\
\text { [33] }\end{array}$ & Warthog & bPPD & $\begin{array}{l}\text { INgezim Tu- } \\
\text { berculosis } \\
\text { DR (E) [49] }\end{array}$ & Wild Boar & MPB83 & $\begin{array}{c}\text { bPPD2 } \\
\text { In-house } \\
\text { ELISA [37] }\end{array}$ & Pig & bPPD \\
\hline 10 & $\begin{array}{c}\text { TB } \\
\text { ELISA-VK } \\
{[33]}\end{array}$ & Warthog & bPPD & $\begin{array}{l}\text { In-house } \\
\text { ELISA (E) } \\
\text { [49] }\end{array}$ & Wild Boar & $\begin{array}{c}\text { P22 } \\
\text { complex }\end{array}$ & $\begin{array}{c}\text { EVELISA } \\
{[25]}\end{array}$ & Deer & MPB83 \\
\hline
\end{tabular}

${ }^{1} \mathrm{~F}=$ field samples. ${ }^{2} \mathrm{E}=$ experimental samples.

Table 4. The ten lowest performing tests in non-bovid wildlife ranked based on lowest values for sensitivity, specificity, and diagnostic odds ratio (DOR), with position ' 1 ' being the lowest value out of the ten tests.

\begin{tabular}{|c|c|c|c|c|c|c|c|c|c|}
\hline \multirow{2}{*}{$\begin{array}{l}\text { Ranking } \\
\text { Position }\end{array}$} & \multicolumn{3}{|c|}{ Lowest 10 Tests-Sensitivity } & \multicolumn{3}{|c|}{ Lowest 10 Tests-Specificity } & \multicolumn{3}{|c|}{ Lowest 10 Tests-DOR } \\
\hline & Test & Species & Ag & Test & Species & Ag & Test & Species & Ag \\
\hline 1 & LFD [42] & Badger & $\begin{array}{l}\text { M. bovis whole } \\
\text { cells }\end{array}$ & mnPCR [20] & Deer & $\mathrm{NA}^{1}$ & LFD [42] & Badger & $\begin{array}{c}\text { M. bovis } \\
\text { whole cells }\end{array}$ \\
\hline 2 & CITT [59] & Deer & a/b PPD & PCR [42] & Badger & $\begin{array}{c}\text { M. bovis } \\
\text { whole cells }\end{array}$ & mnPCR [20] & Deer & NA \\
\hline 3 & $\begin{array}{c}\text { GEA } \\
\text { CXCL11 } \\
{[56]}\end{array}$ & Warthog & ESAT-6/CFP10 & $\begin{array}{c}\text { Indirect } \\
\text { ELISA [51] }\end{array}$ & Badger & $\begin{array}{c}\text { P22 } \\
\text { complex }\end{array}$ & PCR [42] & Badger & $\begin{array}{c}\text { M. bovis } \\
\text { whole cells }\end{array}$ \\
\hline 4 & $\begin{array}{l}\text { DPP VetTB } \\
\text { assay [21] }\end{array}$ & Deer & $\begin{array}{c}\text { MPB83/CFP10/ } \\
\text { ESAT-6 }\end{array}$ & $\begin{array}{c}\text { TB } \\
\text { ELISA-VK } \\
{[33]}\end{array}$ & Warthog & bPPD & CITT [59] & Deer & $\mathrm{a} / \mathrm{b}$ PPD \\
\hline 5 & PCR [42] & Badger & $\begin{array}{l}\text { M. bovis whole } \\
\text { cells }\end{array}$ & SITT [53] & Lion & bPPD & SITT [53] & Lion & bPPD \\
\hline 6 & $\begin{array}{c}\text { GEA } \\
\text { CXCL9 [56] }\end{array}$ & Warthog & ESAT-6/CFP10 & $\begin{array}{c}\text { GEA IFN } \gamma \\
{[56]}\end{array}$ & Warthog & $\begin{array}{l}\text { ESAT-6/ } \\
\text { CFP10 }\end{array}$ & $\begin{array}{c}\text { IP-10 assay } \\
\text { [43] }\end{array}$ & Warthog & $\begin{array}{c}\text { ESAT-6, } \\
\text { CFP-10, } \\
\text { TB7.7 } \\
\text { peptides }\end{array}$ \\
\hline 7 & $\begin{array}{c}\text { Phase } \\
\text { Range } \\
\text { Serum Hp } \\
\text { [59] }\end{array}$ & Deer & $\mathrm{Hp}$ & $\begin{array}{c}\text { IP-10 assay } \\
\text { [43] }\end{array}$ & Warthog & $\begin{array}{c}\text { ESAT-6, } \\
\text { CFP-10, } \\
\text { TB7.7 } \\
\text { peptides }\end{array}$ & $\begin{array}{l}\text { Indirect } \\
\text { ELISA [51] }\end{array}$ & Badger & $\begin{array}{c}\text { P22 } \\
\text { complex }\end{array}$ \\
\hline 8 & PCR [55] & Wild Boar & NA & $\begin{array}{c}\text { TB } \\
\text { ELISA-VK } \\
{[55]}\end{array}$ & Wild Boar & bPPD & $\begin{array}{c}\text { Phase } \\
\text { Range } \\
\text { Serum Hp } \\
\text { [59] }\end{array}$ & Deer & $\mathrm{Hp}$ \\
\hline 9 & $\begin{array}{c}\text { STAT-PAK } \\
\text { [53] }\end{array}$ & Lion & NA & $\begin{array}{c}\text { GEA TNF } \alpha \\
{[56]}\end{array}$ & Warthog & $\begin{array}{l}\text { ESAT- } \\
\text { 6/CFP10 }\end{array}$ & $\begin{array}{c}\text { GEA IFN } \gamma \\
{[56]}\end{array}$ & Warthog & $\begin{array}{c}\text { ESAT- } \\
\text { 6/CFP10 }\end{array}$ \\
\hline 10 & $\begin{array}{l}\text { DPP VetTB } \\
\text { assay [21] }\end{array}$ & Deer & $\begin{array}{c}\text { MPB83/CFP10/ } \\
\text { ESAT-6 }\end{array}$ & $\begin{array}{l}\text { DPP VetTB } \\
\text { assay [33] }\end{array}$ & Warthog & $\begin{array}{l}\text { MPB83/ESAT- } \\
6 / \text { CFP10 }\end{array}$ & $\underset{[56]}{\text { GEA TNF }} \alpha$ & Warthog & $\begin{array}{l}\text { ESAT- } \\
\text { 6/CFP10 }\end{array}$ \\
\hline
\end{tabular}

${ }^{1} \mathrm{NA}=$ Not Applicable, was not indicated in the study. As P22 complex and MPB83 appeared in 20/51 of the tests studied (39.2\%), with $10 \%$ of DOR top-ranking tests using P22 complex and $60 \%$ using MPB83, we asked whether they were genuinely better antigens of choice, testing the hypothesis that either MPB83 or P22 were over-represented more than expected by chance alone in the best performing tests using the Fisher's exact test. The $p$ values for a two-tailed test showed that neither P22 $(p=0.67)$ nor MPB83 ( $p=1.08)$ appeared more often in the top-ranking tests than would be expected by chance. Therefore, there was no evidence to indicate they were superior antigens but simply a reflection of how commonly they were used. 


\subsection{Importance of Gold-Standard Testing and Knowledge of Infection Status}

Through critical analysis of the papers examined, it was apparent that the estimated test performance was dependent on whether the diagnostic samples were derived from naturally or experimentally infected animals, and on the definition of infection status (i.e., the gold-standard applied in the study). An example of the importance of the former was the study by Fresco-Taboada et al. [49], in which they tested a series of techniques separately using experimental samples and field samples. As shown in Tables 2 and 3, tests on the field samples showed greater accuracy in comparison to the experimental samples, ranking higher in the data analysis. With respect to the gold-standard of infection, the study by King et al. [27], which was excluded from analysis due to not using culture as the gold-standard to define true infection status, is illustrative. In that study, the diagnostic performance of three tests (IGRA; STAT-PAK; and qPCR) was assessed. The study did not use a true gold-standard test but instead interchangeably trialled the STAT-PAK and IGRA, as gold-standards together to form one gold standard, and as indiviudal gold standards. When calculating DOR, because there was no measure to identify TN, FN, TP, and TN, a DOR of 1.0 was generated for each test, no matter which 'gold standard' method was used, rendering it impossible to determine the true diagnostic value of any of the tests.

\section{Discussion}

This study was intended as a review of the tests available for diagnosing TB in non-bovid species, focusing on immunological tests and highlighting any advances from previous reviews undertaken in 2009 and 2012 [18,19]. Common indicators of diagnostic performance include sensitivity, specificity, PPV, and NPV; however, these factors are insufficient to demonstrate diagnostic performance alone [17]. Sensitivity and specificity indicators are based on a proportion of results showing positive or negative results among diseased or healthy individuals and do not consider cut off values [17]. NPV and PPV are generally not good indicators of diagnostic performance per se as they are dependent on the prevalence of infection and therefore assess diagnostic performance in a context-dependent situation $[17,62]$. For this study, DOR was chosen as the primary method of evaluating diagnostic performance because it serves as a single measure of test performance independent of disease prevalence [17], making comparisons across studies more straightforward. This is the first study to use DOR to assess diagnostic test performance in animals, although it has been used to assess the performance of TB tests in humans, e.g., [63].

Wild boar, badger, and deer were the most common species used in studies, with $27.5 \%$ of studies carried out in suid species (pigs, wild boar, and warthogs). Wild boar, badger and white-tailed deer are all significant maintenance hosts of TB in different countries [3]. Wild boars have been documented across Europe showing marked increase in numbers [64]. Throughout Europe, wild boar are showing higher levels of transmission of $\mathrm{TB}$, without the requirement of livestock to maintain infection in the ecosystem, as reviewed in Gortázar et al., 2012 [65]. This has an impact on the population of wild boar itself but also increases the chance of transmitting the disease to other wildlife [66]. The increased awareness of wild boar as an important vector of animal TB is reflected the increase in the number of papers reporting the use of immunodiagnostics for suids, 14 papers in this report in comparison to only three papers covering a similar span of time in the last review [19]. The performance of diagnostic tests was reported in two new species since the previous reviews: meerkat and African wild dog, both being the focus of one study each. TB in meerkats is similar to that in other mammalian species [67], and their study has shed light on the behaviors and social interactions that may affect transmission of TB within social mammal species [68]. African Wild Dogs are classed as a threatened species that are currently under high pressure of infection which may impact their long-term survival and conservation [50]. A study looked at 21 packs of wild dog in Kruger National Park, where TB is endemic in African buffaloes and found using an IGRA that 20/21 of the packs studied had been sensitized to $M$. bovis, showing an $83 \%$ prevalence of infection [50]. Despite these results, the species is currently considered stable but highlights the potential 
threat that could occur with changes in biological and environmental factors such as habitat availability and reproductive rates [50].

Antigenic targets identified frequently in this study were ESAT-6, CFP10, MPB83 and MPB70. Recombinant proteins like CFP10/ESAT-6 have demonstrated high sensitivity and specificity for TB detection in people in comparison to conventional CMI diagnostics like the TST [69]. CFP10 and ESAT-6 may also be the target of strong antibody-positive responses when included in serology tests for both elephants and wild boar [52,54] but show poor diagnostic performance in badgers, with no significant increase in antibody response associated with disease progression [70]. Therefore, the diagnostic performance of CFP10 and ESAT- 6 antigens cannot be generalized across species, as is the case with many antigenic targets, but does demonstrate potential for accurate detection of TB in certain species. Individually, MPB83 induces high antibody responses across a range of species including cattle, badger, deer, wild boar, and primates [49,71-73]. P22 was described in 2017 [14], and therefore, was not reviewed previously. P22 complex is a mix of 118 different proteins, some of the most abundant being MPB70, MPB83, and ESAT-6 [14]. P22 complex was reported to have reduced cross-reactivity with Mycobacterium avium, having greater sensitivity than other antigenic targets, like bPPD, [14] in different species, including llamas, cattle, goats, pigs, and sheep [74,75]. In our review, although MPB83 and P22 appeared most frequently as antigenic targets in the top-ranking tests according to sensitivity, specificity, or DOR, they did not appear any more frequently than would be expected by chance, their appearance among the best performing tests more likely indicating how commonly these antigens are used. Nonetheless, both antigens gave good performance in a variety of test platforms against a range of non-bovid species. P22 as an antigenic target gave sensitivity and specificity values of $70.1-96.7 \%$ and $75.0-100.0 \%$, respectively, across studies in wild boar, pig, deer, and badgers. Interestingly, the inclusion of multiple antigens usually increases the likelihood of FP occurring, but this was not seen with P22, despite it being a complex of 118 different antigens. When a P22-based ELISA was compared to the diagnostic performance of MPB83 as a target, it produced similar diagnostic results; however, when used in parallel, sensitivity was increased [76]; some infected animals were only detectable using MPB83 antigen, whilst others were only detectable using the P22 complex [76]. This was surprising since MPB83 is an abundant component of P22. Consequently, when used in parallel, a greater range of animal species were detected. More research is required using field samples to compare and validate the potential of P22 across a wider array of species to confirm the findings above.

Serological diagnostics were more common in the present study than CMI tests, with more serological tests appearing in the top ten. Generally, CMI tests are considered to give high sensitivity; however, this was not seen in this review as CMI tests did not appear among the tests with the highest DOR values. In general, the CMI tests were not carried out in suid species but instead in lions and deer, and this could explain the cause of their lower apparent performance, particularly as the high performing tests were carried out in suid species. Suid species are noted to have a detectable humoral response soon after M. bovis exposure which is maintained with disease progression, allowing for rapid detection $[54,77]$. Moreover, as reviewed by Berger, in most species, the humoral antibody response is dependent upon the cell-mediated response initiating a $\mathrm{T}$ helper cell response to activate macrophages and other essential cytokines for antibody activation [78]. However, it has been suggested that suid species have a dichotomy between the humoral and CMI response, meaning that a strong humoral response can occur independently of a cell-mediated response [79-81].

Despite a test having a high accuracy, it did not always correlate with high diagnostic performance, based on DOR. For example, TB ELISA-VK [37], t-bPPD [37], and bPPD2 [37] were all ranked among the top ten performing tests according to DOR but did not appear in the top ten for either sensitivity or specificity. Conversely, the Ingezim TB-CROM [49], Indirect PPD ELISA [33], and TB ELISA-VK [33] appeared in either or both top ten for specificity and sensitivity but not DOR. We reason that DOR is a better metric for assessing 
the performance of a diagnostic test since sensitivity and specificity (as pooled or indiviudal indicators) do not represent discriminatory performance, since a high sensitivity can be accompanied by a low specificity, as shown particularly for the TB ELISA-VK [33]. In contrast, DOR is a combination of both sensitivity and specificity, increasing when they become near perfect.

\section{Materials and Methods}

\subsection{Literature Search and Exclusion Criteria}

Using NCBI PubMed, we identified appropriate papers written in English from 2012, when the last review [19] was carried out. A total of 162 papers were found using the search criteria: ((((wild*) AND (mycobacteri*)) AND (diagnos*)) AND ((“2012/09/01"[DatePublication]: "3000"[Date-Publication]))) AND (immun*). For each of the 162 papers, the abstracts were reviewed, looking for details of the use of (immuno)diagnostics for MTBC infection in non-bovid species. Papers were excluded if they were exclusively based on bovid species, mycobacteria that do not cause TB infection such as Mycobacterium avium subspecies paratuberculosis or used exclusively non-immunological based diagnostic tests, with the exception of Stewart et al. [42] as it reported a novel immunochromatographic lateral flow assay specific for Mycobacterium bovis cells. Additionally, previous review articles were excluded from data collection and statistical analysis but were recorded and reviewed for completeness.

From this, forty-one papers were recorded as relevant from which data were collected, including the species under study, whether TB was experimentally or naturally induced, the mycobacterium species, the test used and how it was employed, the target of the test (i.e., antigen(s)), sample size and type of sample, relative sensitivity and specificity of the diagnostic technique, the NPV and PPV, and the associated cut-off values. If any of the information was not present or had not been mentioned, this was noted.

\subsection{Statistical Analysis}

Using the sample size and infection status, TP and TN, and FP and FN values were calculated from the 41 papers where possible, if not already stated. Studies with missing values, e.g., for sensitivity, specificity, PPV, and NPV, were calculated where possible from the reported data using the following formulae:

$$
\begin{gathered}
\text { sensitivity }=\mathrm{TP} /(\mathrm{TP}+\mathrm{FN}) \\
\text { specificity }=\mathrm{TN} /(\mathrm{TN}+\mathrm{FP}) \\
\mathrm{NPV}=\mathrm{TN} /(\mathrm{TN}+\mathrm{FN}) \\
\mathrm{PPV}=\mathrm{TP} /(\mathrm{TP}+\mathrm{FP})
\end{gathered}
$$

Following this, the 95\% CI surrounding the sensitivity and specificity were noted, if available, or calculated if not. The DOR for each individual test was calculated using the formula:

$$
\mathrm{DOR}=(\mathrm{TP} / \mathrm{FN}) /(\mathrm{FP} / \mathrm{TN})
$$

The DOR was then adjusted, by adding 0.5 to each of the cells in the contingency table, to account for the tests that had ' 0 ' values in any of the TN, TP, FP, FN values. The DOR adjustment was applied across all studies to prevent introducing bias to the data. The adjusted DOR was then used to calculate the 95\% CI using the formulae below. All calculations were rounded to 1 decimal place. All formulae for the calculations outlined were sourced from [17].

$$
\begin{gathered}
\text { Standard Error }(\mathrm{SE})(\operatorname{lnDOR})=\sqrt{\frac{1}{T P}}+\frac{1}{F N}+\frac{1}{F P}+\frac{1}{T N}, \\
95 \% \mathrm{CI}=\operatorname{lnDOR} \pm 1.96 \times \mathrm{SE}(\operatorname{lnDOR})
\end{gathered}
$$




$$
\text { True } 95 \% \mathrm{CI}={ }^{\prime}=\mathrm{EXP}( \pm \mathrm{CI})^{\prime}
$$

The most common species, techniques, and antigenic targets were noted, and the data used to rank the tests in order of sensitivity, specificity, and DOR. All study data included in statistical analysis involving test sensitivity and specificity were established using culture as a gold-standard to confirm infection status.

\section{Conclusions}

In conclusion, a variety of diagnostic tests are now available for an array of wildlife species, with increasing variety of species being studied. The focus of this review was on diagnostic tests that detect or measure the host immune response to infection. From the current review, it was evident that serological tests are surpassing tests like the TST and even other CMI-based tests, such as IGRA for diagnostic performance. Obtaining proof of high accuracy in tests is still an issue, restricting validation of many tests. The current review used DOR to evaluate diagnostic performance, which to the best of our knowledge has not been used previously for assessing TB diagnostic tests in animals. P22 complex was identified as a promising, new antigenic target, which alongside MPB83 demonstrated potential for use as an accurate seroantigenic target. We believe these conclusions to be consistent with the evidence and arguments presented.

Author Contributions: Conceptualization, M.C.; methodology, R.T. and M.C.; formal analysis, R.T.; data curation, R.T.; writing-original draft preparation, R.T.; writing-review and editing, M.C.; supervision, M.C.; project administration, M.C. Both authors have read and agreed to the published version of the manuscript.

Funding: This research received no external funding.

Institutional Review Board Statement: Not applicable.

Informed Consent Statement: Not applicable.

Data Availability Statement: Data are either contained within the article or relate to 3rd Party Data. Full references are provided for these 3rd Party Data but restrictions may apply to their availability.

Conflicts of Interest: The authors declare no conflict of interest.

\section{References}

1. Gagneux, S. Host-pathogen coevolution in human tuberculosis. Philos. Trans. R. Soc. Lond. B Biol. Sci. 2012, 367, 850-859. [CrossRef]

2. Brites, D.; Loiseau, C.; Menardo, F.; Borrell, S.; Boniotti, M.B.; Warren, R.; Dippenaar, A.; Parsons, S.D.C.; Beisel, C.; Behr, M.A.; et al. A new phylogenetic framework for the animal-adapted Mycobacterium tuberculosis complex. Front. Microbiol. $2018,9,2820$. [CrossRef]

3. Palmer, M.V. Mycobacterium bovis: Characteristics of wildlife reservoir hosts. Transbound. Emerg. Dis. 2013, 60, 1-13. [CrossRef]

4. Miller, M.; Olea-Popelka, F. One health in the shrinking world: Experiences with tuberculosis at the human-livestock-wildlife interface. Comp. Immunol. Microbiol. Infect. Dis. 2013, 36, 263-268. [CrossRef] [PubMed]

5. Fitzgerald, S.D.; Kaneene, J.B. Wildlife reservoirs of bovine tuberculosis worldwide: Hosts, pathology, surveillance, and control. Vet. Pathol. 2013, 50, 488-499. [CrossRef] [PubMed]

6. Dalovisio, J.R.; Stetter, M.; Mikota-Wells, S. Rhinoceros' rhinorrhea: Cause of an outbreak of infection due to airborne Mycobacterium bovis in zookeepers. Clin. Infect. Dis. 1992, 15, 598-600. [CrossRef]

7. Lécu, A.; Ball, R. Mycobacterial infections in zoo animals: Relevance, diagnosis and management. Int. Zoo Yearb. 2011, 45, 183-202. [CrossRef]

8. Silva, D.A.V.D.; Siconelli, M.J.L.; Bürger, K.P.; Keid, L.B. Comparison between tests for tuberculosis diagnosis in slaughtered bovines. Arq. Inst. Biológico 2018, 85, 85. [CrossRef]

9. Salfinger, M.; Pfyffer, G.E. The new diagnostic mycobacteriology laboratory. Eur. J. Clin. Microbiol. Infect. Dis. 1994, 13, 961-979. [CrossRef]

10. Pfyffer, G.E. Mycobacterium: General characteristics, laboratory detection, and staining procedures. In Manual of Clinical Microbiology, 11th ed.; Jorgensen, J.H., Pfaller, M.A., Carroll, K.C., Funke, G., Landry, M.L., Richter, S.S., Warnock, D.W., Eds.; ASM Press: Washington, DC, USA, 2015; Volume 1, pp. 536-569.

11. Hines, N.; Payeur, J.B.; Hoffman, L.J. Comparison of the recovery of Mycobacterium bovis isolates using the BACTEC MGIT 960 system, BACTEC 460 system, and Middlebrook 7H10 and 7H11 solid media. J. Vet. Diag. Investig. 2006, 18, 243-250. [CrossRef] 
12. Welsh, M.D.; Cunningham, R.T.; Corbett, D.M.; Girvin, R.M.; McNair, J.; Skuce, R.A.; Bryson, D.G.; Pollock, J.M. Influence of pathological progression on the balance between cellular and humoral immune responses in bovine tuberculosis. Immunology 2005, 114, 101-111. [CrossRef] [PubMed]

13. Pollock, J.M.; McNair, J.; Welsh, M.D.; Girvin, R.M.; Kennedy, H.E.; Mackie, D.P.; Neill, S.D. Immune responses in bovine tuberculosis. Tuberculosis 2001, 81, 103-107. [CrossRef] [PubMed]

14. Infantes-Lorenzo, J.A.; Moreno, I.; Risalde, M.L.A.; Roy, A.; Villar, M.; Romero, B.; Ibarrola, N.; de la Fuente, J.; Puentes, E.; de Juan, L.; et al. Proteomic characterisation of bovine and avian purified protein derivatives and identification of specific antigens for serodiagnosis of bovine tuberculosis. Clin. Proteom. 2017, 14, 36. [CrossRef] [PubMed]

15. de Lisle, G.W.; Bengis, R.G.; Schmitt, S.M.; O’Brien, D.J. Tuberculosis in free-ranging wildlife: Detection, diagnosis and management. Rev. Sci. Tech. 2002, 21,317-334. [CrossRef]

16. Higgins, D.A. The skin inflammatory response of the badger (Meles meles). Br. J. Exp. Pathol. 1985, 66, 643-653.

17. Glas, A.S.; Lijmer, J.G.; Prins, M.H.; Bonsel, G.J.; Bossuyt, P.M. The diagnostic odds ratio: A single indicator of test performance. J. Clin. Epidemiol. 2003, 56, 1129-1135. [CrossRef]

18. Chambers, M.A. Review of the diagnosis and study of tuberculosis in non-bovine wildlife species using immunological methods. Transbound. Emerg. Dis. 2009, 56, 215-227. [CrossRef]

19. Chambers, M.A. Review of the diagnosis of tuberculosis in non-bovid wildlife species using immunological methods-An update of published work since 2009. Transbound. Emerg. Dis. 2013, 60, 14-27. [CrossRef]

20. Chu, C.S.; Yu, C.Y.; Chen, C.T.; Su, Y.C. Mycobacterium tuberculosis and M. bovis infection in Feedlot Deer (Cervus unicolor swinhoei and C. nippon taiouanus) in Taiwan. J. Microbiol. Immunol. Infect. 2012, 45, 426-434. [CrossRef] [PubMed]

21. Lyashchenko, K.P.; Greenwald, R.; Esfandiari, J.; O’Brien, D.J.; Schmitt, S.M.; Palmer, M.V.; Waters, W.R. Rapid detection of serum antibody by dual-path platform VetTB assay in white-tailed deer infected with Mycobacterium bovis. Clin. Vaccine Immunol. 2013, 20, 907-911. [CrossRef] [PubMed]

22. Morar, D.; Schreuder, J.; Meny, M.; van Kooten, P.J.; Tijhaar, E.; Michel, A.L.; Rutten, V.P. Towards establishing a rhinoceros-specific interferon-gamma (IFN-gamma) assay for diagnosis of tuberculosis. Transbound. Emerg. Dis. 2013, 60, 60-66. [CrossRef] [PubMed]

23. Richomme, C.; Boadella, M.; Courcoul, A.; Durand, B.; Drapeau, A.; Corde, Y.; Hars, J.; Payne, A.; Fediaevsky, A.; Boschiroli, M.L. Exposure of wild boar to Mycobacterium tuberculosis complex in France since 2000 is consistent with the distribution of bovine tuberculosis outbreaks in cattle. PLoS ONE 2013, 8, e77842. [CrossRef] [PubMed]

24. Wadhwa, A.; Johnson, R.E.; Mackintosh, C.G.; Griffin, J.F.; Waters, W.R.; Bannantine, J.P.; Eda, S. Use of ethanol extract of Mycobacterium bovis for detection of specific antibodies in sera of farmed red deer (Cervus elaphus) with bovine tuberculosis. BMC Vet. Res. 2013, 9, 256. [CrossRef] [PubMed]

25. Wadhwa, A.; Johonson, R.E.; Eda, K.; Waters, W.R.; Palmer, M.V.; Bannantine, J.P.; Eda, S. Evaluation of ethanol vortex ELISA for detection of bovine tuberculosis in cattle and deer. BMC Vet. Res. 2014, 10, 147. [CrossRef]

26. Che' Amat, A.; Gonzalez-Barrio, D.; Ortiz, J.A.; Diez-Delgado, I.; Boadella, M.; Barasona, J.A.; Bezos, J.; Romero, B.; Armenteros, J.A.; Lyashchenko, K.P.; et al. Testing Eurasian wild boar piglets for serum antibodies against Mycobacterium bovis. Prev. Vet. Med. 2015, 121, 93-98. [CrossRef]

27. King, H.C.; Murphy, A.; James, P.; Travis, E.; Porter, D.; Sawyer, J.; Cork, J.; Delahay, R.J.; Gaze, W.; Courtenay, O.; et al. Performance of a noninvasive test for detecting Mycobacterium bovis shedding in european badger (Meles meles) populations. J. Clin. Microbiol. 2015, 53, 2316-2323. [CrossRef]

28. Miller, M.A.; Greenwald, R.; Lyashchenko, K.P. Potential for serodiagnosis of tuberculosis in black rhinoceros (Diceros bicornis). J. Zoo Wildl. Med. 2015, 46, 100-104. [CrossRef]

29. Tomlinson, A.J.; Chambers, M.A.; McDonald, R.A.; Delahay, R.J. Association of quantitative interferon-gamma responses with the progression of naturally acquired Mycobacterium bovis infection in wild European badgers (Meles meles). Immunology 2015, 144, 263-270. [CrossRef]

30. Vogelnest, L.; Hulst, F.; Thompson, P.; Lyashchenko, K.P.; Herrin, K.A. Diagnosis and management of tuberculosis (Mycobacterium tuberculosis) in an Asian elephant (Elephas maximus) with a newborn calf. J. Zoo Wildl. Med. 2015, 46, 77-85. [CrossRef]

31. Clarke, C.; Patterson, S.J.; Drewe, J.A.; van Helden, P.D.; Miller, M.A.; Parsons, S.D. Development and evaluation of a diagnostic cytokine-release assay for Mycobacterium suricattae infection in meerkats (Suricata suricatta). BMC Vet. Res. 2017, 13, 2. [CrossRef] [PubMed]

32. Miller, M.; Buss, P.; de Klerk-Lorist, L.M.; Hofmeyr, J.; Hausler, G.; Lyashchenko, K.; Lane, E.P.; Botha, L.; Parsons, S.; van Helden, P. Application of rapid serologic tests for detection of Mycobacterium bovis infection in free-ranging warthogs (Phacochoerus africanus)_Implications for antemortem disease screening. J. Wildl. Dis. 2016, 52, 180-182. [CrossRef]

33. Roos, E.O.; Buss, P.; de Klerk-Lorist, L.M.; Hewlett, J.; Hausler, G.A.; Rossouw, L.; McCall, A.J.; Cooper, D.; van Helden, P.D.; Parsons, S.D.C.; et al. Test performance of three serological assays for the detection of Mycobacterium bovis infection in common warthogs (Phacochoerus africanus). Vet. Immunol. Immunopathol. 2016, 182, 79-84. [CrossRef]

34. Yakubu, Y.; Ong, B.L.; Zakaria, Z.; Hassan, L.; Mutalib, A.R.; Ngeow, Y.F.; Verasahib, K.; Razak, M.F. Evidence and potential risk factors of tuberculosis among captive Asian elephants and wildlife staff in Peninsular Malaysia. Prev. Vet. Med. 2016, 125, 147-153. [CrossRef] [PubMed]

35. Busch, F.; Bannerman, F.; Liggett, S.; Griffin, F.; Clarke, J.; Lyashchenko, K.P.; Rhodes, S. Control of bovine tuberculosis in a farmed red deer herd in England. Vet. Rec. 2017, 180, 68. [CrossRef] [PubMed] 
36. Buzdugan, S.N.; Chambers, M.A.; Delahay, R.J.; Drewe, J.A. Quantitative interferon-gamma responses predict future disease progression in badgers naturally infected with Mycobacterium bovis. Epidemiol. Infect. 2017, 145, 3204-3213. [CrossRef]

37. Cardoso-Toset, F.; Luque, I.; Carrasco, L.; Jurado-Martos, F.; Risalde, M.A.; Venteo, A.; Infantes-Lorenzo, J.A.; Bezos, J.; Rueda, P.; Tapia, I.; et al. Evaluation of five serologic assays for bovine tuberculosis surveillance in domestic free-range pigs from southern Spain. Prev. Vet. Med. 2017, 137, 101-104. [CrossRef]

38. Perez de Val, B.; Napp, S.; Velarde, R.; Lavin, S.; Cervera, Z.; Singh, M.; Allepuz, A.; Mentaberre, G. Serological Follow-up of Tuberculosis in a Wild Boar Population in Contact with Infected Cattle. Transbound. Emerg. Dis. 2017, 64, 275-283. [CrossRef] [PubMed]

39. Olivier, T.T.; Viljoen, I.M.; Hofmeyr, J.; Hausler, G.A.; Goosen, W.J.; Tordiffe, A.S.W.; Buss, P.; Loxton, A.G.; Warren, R.M.; Miller, M.A.; et al. Development of a gene expression assay for the diagnosis of Mycobacterium bovis infection in african lions (Panthera leo). Transbound. Emerg. Dis. 2017, 64, 774-781. [CrossRef] [PubMed]

40. Parsons, S.D.C.; Morar-Leather, D.; Buss, P.; Hofmeyr, J.; McFadyen, R.; Rutten, V.; van Helden, P.D.; Miller, M.A.; Michel, A.L. The kinetics of the humoral and interferon-gamma immune responses to experimental Mycobacterium bovis infection in the white rhinoceros (Ceratotherium simum). Front. Immunol. 2017, 8, 1831. [CrossRef]

41. Rosen, L.E.; Hanyire, T.G.; Dawson, J.; Foggin, C.M.; Michel, A.L.; Huyvaert, K.P.; Miller, M.A.; Olea-Popelka, F.J. Tuberculosis serosurveillance and management practices of captive African elephants (Loxodonta africana) in the Kavango-Zambezi Transfrontier Conservation Area. Transbound. Emerg. Dis. 2018, 65, 344-354. [CrossRef]

42. Stewart, L.D.; Tort, N.; Meakin, P.; Argudo, J.M.; Nzuma, R.; Reid, N.; Delahay, R.J.; Ashford, R.; Montgomery, W.I.; Grant, I.R. Development of a novel immunochromatographic lateral flow assay specific for Mycobacterium bovis cells and its application in combination with immunomagnetic separation to test badger faeces. BMC Vet. Res. 2017, 13, 131. [CrossRef]

43. Roos, E.O.; Olea-Popelka, F.; Buss, P.; de Klerk-Lorist, L.M.; Cooper, D.; Warren, R.M.; van Helden, P.D.; Parsons, S.D.C.; Miller, M.A. IP-10: A potential biomarker for detection of Mycobacterium bovis infection in warthogs (Phacochoerus africanus). Vet. Immunol. Immunopathol. 2018, 201, 43-48. [CrossRef]

44. Roos, E.O.; Olea-Popelka, F.; Buss, P.; de Klerk-Lorist, L.M.; Cooper, D.; van Helden, P.D.; Parsons, S.D.C.; Miller, M.A. Seroprevalence of Mycobacterium bovis infection in warthogs (Phacochoerus africanus) in bovine tuberculosis-endemic regions of South Africa. Transbound. Emerg. Dis. 2018, 65, 1182-1189. [CrossRef]

45. Roos, E.O.; Olea-Popelka, F.; Buss, P.; Hausler, G.A.; Warren, R.; van Helden, P.D.; Parsons, S.D.C.; de Klerk-Lorist, L.M.; Miller, M.A. Measuring antigen-specific responses in Mycobacterium bovis-infected warthogs (Phacochoerus africanus) using the intradermal tuberculin test. BMC Vet. Res. 2018, 14, 360. [CrossRef] [PubMed]

46. Santos, N.; Nunes, T.; Fonseca, C.; Vieira-Pinto, M.; Almeida, V.; Gortazar, C.; Correia-Neves, M. Spatial analysis of wildlife tuberculosis based on a serologic survey using dried blood spots, portugal. Emerg. Infect. Dis. 2018, 24, 2169-2175. [CrossRef] [PubMed]

47. Chileshe, J.; Roos, E.O.; Goosen, W.J.; Buss, P.; Hausler, G.; Rossouw, L.; Manemela, T.; van Helden, P.; Warren, R.; Parsons, S.D.; et al. An interferon-gamma release assay for the diagnosis of the Mycobacterium bovis infection in white rhinoceros (Ceratotherium simum). Vet. Immunol. Immunopathol. 2019, 217, 109931. [CrossRef] [PubMed]

48. Dalley, D.; Lesellier, S.; Salguero, F.J.; Chambers, M.A. Purification and characterisation of badger IgA and its detection in the context of tuberculosis. Vet. Sci. 2019, 6, 89. [CrossRef]

49. Fresco-Taboada, A.; Risalde, M.A.; Gortazar, C.; Tapia, I.; Gonzalez, I.; Venteo, A.; Sanz, A.; Rueda, P. A lateral flow assay for the rapid diagnosis of Mycobacterium bovis infection in wild boar. Transbound. Emerg. Dis. 2019, 66, 2175-2179. [CrossRef]

50. Higgitt, R.L.; Louis van Schalkwyk, O.; de Klerk-Lorist, L.M.; Buss, P.E.; Caldwell, P.; Rossouw, L.; Manamela, T.; Hausler, G.A.; Hewlett, J.; Mitchell, E.P.; et al. Mycobacterium bovis infection in african wild dogs, kruger national park, south africa. Emerg. Infect. Dis. 2019, 25, 1425-1427. [CrossRef]

51. Infantes-Lorenzo, J.A.; Dave, D.; Moreno, I.; Anderson, P.; Lesellier, S.; Gormley, E.; Dominguez, L.; Balseiro, A.; Gortazar, C.; Dominguez, M.; et al. New serological platform for detecting antibodies against Mycobacterium tuberculosis complex in European badgers. Vet. Med. Sci. 2019, 5, 61-69. [CrossRef]

52. Kerr, T.J.; de Waal, C.R.; Buss, P.E.; Hofmeyr, J.; Lyashchenko, K.P.; Miller, M.A. Seroprevalence of Mycobacterium tuberculosis complex in free-ranging african elephants (Loxodonta africana) in kruger national park, south africa. J. Wildl. Dis. 2019, 55, 923-927. [CrossRef]

53. Miller, M.A.; Buss, P.; Sylvester, T.T.; Lyashchenko, K.P.; deKlerk-Lorist, L.M.; Bengis, R.; Hofmeyr, M.; Hofmeyr, J.; Mathebula, N.; Hausler, G.; et al. Mycobacterium Bovis in free-ranging lions (Panthera Leo)—Evaluation of serological and tuberculin skin tests for detection of infection and disease. J. Zoo Wildl. Med. 2019, 50, 7-15. [CrossRef] [PubMed]

54. Miller, M.A.; Gortazar, C.; Roos, E.O.; Risalde, M.A.; Johnathan-Lee, A.; Sridhara, A.A.; Lyashchenko, K.P. Serological reactivity to MPB83 and CFP10/ESAT-6 antigens in three suid hosts of Mycobacterium bovis infection. Vet. Microbiol. 2019, 235, 285-288. [CrossRef]

55. Richomme, C.; Courcoul, A.; Moyen, J.L.; Reveillaud, E.; Maestrini, O.; de Cruz, K.; Drapeau, A.; Boschiroli, M.L. Tuberculosis in the wild boar: Frequentist and Bayesian estimations of diagnostic test parameters when Mycobacterium bovis is present in wild boars but at low prevalence. PLoS ONE 2019, 14, e222661. [CrossRef] [PubMed] 
56. Roos, E.O.; Scott, L.A.; Ndou, S.; Olea-Popelka, F.; Buss, P.E.; de Klerk-Lorist, L.M.; Warren, R.M.; van Helden, P.D.; Sylvester, T.T.; Miller, M.A.; et al. Cytokine gene expression assay as a diagnostic tool for detection of Mycobacterium bovis infection in warthogs (Phacochoerus africanus). Sci. Rep. 2019, 9, 16525. [CrossRef]

57. Thomas, J.; Infantes-Lorenzo, J.A.; Moreno, I.; Cano-Terriza, D.; de Juan, L.; Garcia-Bocanegra, I.; Dominguez, L.; Dominguez, M.; Gortazar, C.; Risalde, M.A. Validation of a new serological assay for the identification of Mycobacterium tuberculosis complexspecific antibodies in pigs and wild boar. Prev. Vet. Med. 2019, 162, 11-17. [CrossRef] [PubMed]

58. Thomas, J.; Infantes-Lorenzo, J.A.; Moreno, I.; Romero, B.; Garrido, J.M.; Juste, R.; Dominguez, M.; Dominguez, L.; Gortazar, C.; Risalde, M.A. A new test to detect antibodies against Mycobacterium tuberculosis complex in red deer serum. Vet. J. 2019, 244, 98-103. [CrossRef]

59. Vicente, J.; Martinez-Guijosa, J.; Tvarijonaviciute, A.; Fernandez-de Mera, I.G.; Gortazar, C.; Ceron, J.J.; Martinez-Subiela, S. Serum haptoglobin response in red deer naturally infected with tuberculosis. Comp. Immunol. Microbiol. Infect. Dis. 2019, 64, 25-30. [CrossRef]

60. Viljoen, I.M.; Sylvester, T.T.; Parsons, S.D.C.; Millar, R.P.; Helden, P.D.V.; Miller, M.A. Performance of the tuberculin skin test in Mycobacterium Bovis-exposed and -unexposed african lions (Panthera Leo). J. Wildl. Dis. 2019, 55, 537-543. [CrossRef]

61. Goosen, W.J.; Cooper, D.; Warren, R.M.; Miller, M.A.; van Helden, P.D.; Parsons, S.D. The evaluation of candidate biomarkers of cell-mediated immunity for the diagnosis of Mycobacterium bovis infection in African buffaloes (Syncerus caffer). Vet. Immunol. Immunopathol. 2014, 162, 198-202. [CrossRef]

62. Altman, D.G.; Bland, J.M. Diagnostic tests 2: Predictive values. BMJ 1994, 309, 102. [CrossRef]

63. Greco, S.; Girardi, E.; Navarra, A.; Saltini, C. Current evidence on diagnostic accuracy of commercially based nucleic acid amplification tests for the diagnosis of pulmonary tuberculosis. Thorax 2006, 61, 783-790. [CrossRef]

64. Massei, G.; Kindberg, J.; Licoppe, A.; Gacic, D.; Sprem, N.; Kamler, J.; Baubet, E.; Hohmann, U.; Monaco, A.; Ozolins, J.; et al. Wild boar populations up, numbers of hunters down? A review of trends and implications for Europe. Pest. Manag. Sci. 2015, 71, 492-500. [CrossRef] [PubMed]

65. Gortázar, C.; Delahay, R.J.; McDonald, R.A.; Boadella, M.; Wilson, G.J.; Gavier-Widen, D.; Acevedo, P. The status of tuberculosis in European wild mammals. Mammal. Rev. 2012, 42, 193-206. [CrossRef]

66. Barasona, J.A.; Gortazar, C.; de la Fuente, J.; Vicente, J. Host richness increases tuberculosis disease risk in game-managed areas. Microorganisms 2019, 7, 182. [CrossRef]

67. Drewe, J.A.; Foote, A.K.; Sutcliffe, R.L.; Pearce, G.P. Pathology of Mycobacterium bovis infection in wild meerkats (Suricata suricatta). J. Comp. Pathol. 2009, 140, 12-24. [CrossRef] [PubMed]

68. Drewe, J.A. Who infects whom? Social networks and tuberculosis transmission in wild meerkats. Proc. Biol. Sci. 2010, 277, 633-642. [CrossRef]

69. Hemmati, M.; Seghatoleslam, A.; Rasti, M.; Ebadat, S.; Mosavari, N.; Habibagahi, M.; Taheri, M.; Sardarian, A.R.; Mostafavi-Pour, Z. Expression and purification of recombinant Mycobacterium tuberculosis (TB) antigens, ESAT-6, CFP-10 and ESAT- 6/CFP-10 and their diagnosis potential for detection of TB patients. Iran. Red Crescent Med. J. 2011, 13, 556-563.

70. Ashford, R.T.; Anderson, P.; Waring, L.; Dave, D.; Smith, F.; Delahay, R.J.; Gormley, E.; Chambers, M.A.; Sawyer, J.; Lesellier, S. Evaluation of the dual path platform (DPP) VetTB assay for the detection of Mycobacterium bovis infection in badgers. Prev. Vet. Med. 2020, 180, 105005. [CrossRef]

71. Lyashchenko, K.P.; Greenwald, R.; Esfandiari, J.; Greenwald, D.; Nacy, C.A.; Gibson, S.; Didier, P.J.; Washington, M.; Szczerba, P.; Motzel, S.; et al. PrimaTB STAT-PAK assay, a novel, rapid lateral-flow test for tuberculosis in nonhuman primates. Clin. Vaccine Immunol. 2007, 14, 1158-1164. [CrossRef]

72. Waters, W.R.; Palmer, M.V.; Bannantine, J.P.; Whipple, D.L.; Greenwald, R.; Esfandiari, J.; Andersen, P.; McNair, J.; Pollock, J.M.; Lyashchenko, K.P. Antigen recognition by serum antibodies in white-tailed deer (Odocoileus virginianus) experimentally infected with Mycobacterium bovis. Clin. Diagn. Lab. Immunol. 2004, 11, 849-855. [CrossRef] [PubMed]

73. Waters, W.R.; Palmer, M.V.; Thacker, T.C.; Bannantine, J.P.; Vordermeier, H.M.; Hewinson, R.G.; Greenwald, R.; Esfandiari, J.; McNair, J.; Pollock, J.M.; et al. Early antibody responses to experimental Mycobacterium bovis infection of cattle. Clin. Vaccine Immunol. 2006, 13, 648-654. [CrossRef]

74. Infantes-Lorenzo, J.A.; Moreno, I.; Roy, A.; Risalde, M.A.; Balseiro, A.; de Juan, L.; Romero, B.; Bezos, J.; Puentes, E.; Akerstedt, J.; et al. Specificity of serological test for detection of tuberculosis in cattle, goats, sheep and pigs under different epidemiological situations. BMC Vet. Res. 2019, 15, 70. [CrossRef]

75. Infantes-Lorenzo, J.A.; Whitehead, C.E.; Moreno, I.; Bezos, J.; Roy, A.; Dominguez, L.; Dominguez, M.; Salguero, F.J. Development and evaluation of a serological assay for the diagnosis of tuberculosis in alpacas and llamas. Front. Vet. Sci. 2018, 5, 189. [CrossRef]

76. Arrieta-Villegas, C.; Infantes-Lorenzo, J.A.; Bezos, J.; Grasa, M.; Vidal, E.; Mercader, I.; Singh, M.; Domingo, M.; de Juan, L.; Perez de Val, B. Evaluation of P22 antigenic complex for the immuno-diagnosis of tuberculosis in BCG vaccinated and unvaccinated goats. Front. Vet. Sci. 2020, 7, 374. [CrossRef] [PubMed]

77. Barasona, J.A.; Barroso-Arevalo, S.; Rivera, B.; Gortazar, C.; Sanchez-Vizcaino, J.M. Detection of Antibodies against Mycobacterium bovis in Oral Fluid from Eurasian Wild Boar. Pathogens 2020, 9, 242. [CrossRef] [PubMed]

78. Berger, A. Th1 and Th2 responses: What are they? BMJ 2000, 321, 424. [CrossRef] 
79. Boadella, M.; Lyashchenko, K.; Greenwald, R.; Esfandiari, J.; Jaroso, R.; Carta, T.; Garrido, J.M.; Vicente, J.; de la Fuente, J.; Gortazar, C. Serologic tests for detecting antibodies against Mycobacterium bovis and Mycobacterium avium subspecies paratuberculosis in Eurasian wild boar (Sus scrofa scrofa). J. Vet. Diagn. Investig. 2011, 23, 77-83. [CrossRef]

80. De Bruin, M.G.; De Visser, Y.E.; Kimman, T.G.; Bianchi, A.T. Time course of the porcine cellular and humoral immune responses in vivo against pseudorabies virus after inoculation and challenge: Significance of in vitro antigenic restimulation. Vet. Immunol. Immunopathol. 1998, 65, 75-87. [CrossRef]

81. Kimman, T.G.; De Bruin, T.M.; Voermans, J.J.; Peeters, B.P.; Bianchi, A.T. Development and antigen specificity of the lymphoproliferation responses of pigs to pseudorabies virus: Dichotomy between secondary B- and T-cell responses. Immunology 1995, 86, $372-378$. 